\title{
PERIPHERAL TUBERCULAR NEURITIS: AN UNUSUAL PRESENTATION OF CERVICAL NERVE
}

\author{
Vipin R. Ekhar ${ }^{1}$, Sachin V. Rane², Ritesh N. Shelkar³, S. K. T. Jain4, Ashok Garje ${ }^{5}$
}

\section{HOW TO CITE THIS ARTICLE:}

Vipin R. Ekhar, Sachin V. Rane, Ritesh N. Shelkar, S. K. T. Jain, Ashok Garje. "Peripheral Tubercular Neuritis: An Unusual Presentation of Cervical Nerve". Journal of Evolution of Medical and Dental Sciences 2014; Vol. 3, Issue 20, May 19; Page: 5371-5374, DOI: 10.14260/jemds/2014/2599

\begin{abstract}
Tuberculosis, one of the major infectious diseases in India. It can involve many organs of human body but the primary involvement of nerve tissue is very unusual \& uncommon. Present study reports 69 yrs. old lady with left sided neck swelling which was first diagnosed as External jugular vein thrombosis. But histopathological features of excised specimen showed tubercular neuritis.
\end{abstract}

KEYWORDS: Tuberculosis, neuritis, anti-tubercular drugs.

INTRODUCTION: The number of true infectious diseases of peripheral nerves is small. Peripheral polyneuropathy commonly occurs following exanthematous fevers and as a complication of various acute bacterial infections, but it is highly doubtful whether there is direct invasion of the nerves by micro-organisms.The causative association of peripheral neuropathy with tuberculous infection is controversial. Many possibilities have been suggested; with no definite single cause. The tubercular nerve involvement is very rare. Few cases of cranial nerve involvement have been reported, however peripheral nerve involvement by tubercular granulomas is not reported in available literature. This report describes rare finding of tuberculous granulomas in cervical region with tuberculous involvement of a peripheral nerve-Greater auricular nerve (C2, C3) in a patient, who clinically presented with painful neck swelling. The granulomas may have disrupted the endoneurial blood supply, producing the acute Wallerian-type degeneration of the nerve which was perceived by the patient as pain in the neck swelling. We want to stress the fact that, it should never be assumed that neuropathy in patients with tuberculosis is iatrogenic, and the possibility of a primary affection of the nerves should be considered.

CASE REPORT: 69 yrs. old female patient presented to ENT OPD with complaints of swelling over left side of neck since 3 months \& pain over the swelling since 2 weeks. The patient noticed the swelling 3 months back about $3 \mathrm{cms}$ from the angle of mandible and had the history that the swelling slowly elongated in the downward direction so that by the time she presented to us it was about $5 \mathrm{~cm}$ in length and $1 \mathrm{~cm}$ in width (Fig. I). She was also having severe pain in the region and the swelling was gradually increasing in length. No history of similar complaints in past or Koch's or Koch's contact. There was no history of similar swelling in any other part of the body. There was no history of trauma to that area, no history of bleeding disorder, diabetes mellitus or hypertension. On examination there was a cord-like linear swelling about $5 \mathrm{~cm}$ in length on the antero-lateral part of neck overlying the sternocleidomastoid muscle. The swelling was extremely tender on palpation. The skin over the area was inflamed especially towards the lower end of the swelling. There was no other significant cervical lymphadenopathy. We kept the diagnosis of acute cervical lymphadenopathy and started her on antibiotics and anti-inflammatory drugs. In spite of treatment, the lesion gradually increased in size and continued to be tender. 
So we decided to investigate her further. Her routine hematological work-up was normal. Kidney function test and Blood sugar level were within normal range. Keeping possibility of tubercular etiology, X-ray chest was done which was WNL, Montoux Test and Sputum AFB was negative \& ESR was $14 \mathrm{~mm} / \mathrm{hr}$. Her HIV status was non-reactive. Ultrasonography of the neck revealed a hypoechoeic lesion $5 \mathrm{~cm}$ in length and $0.8 \mathrm{~cm}$ in width from the retromandibular region to mid cervical region suggestive of External Jugular Vein (EJV) Thrombosis. Local colour doppler study confirmed absence of blood flow in the affected part of EJV. CT Neck was done, which also revealed isolated EJV thrombosis with normal other neck vessels and no other abnormality.

We now went ahead to find out the cause for isolated EJV thrombosis, which is very unusual. The coagulation studies were within normal limits. We also did her CT Abdomen and pelvis to rule out occult malignancies which can give rise to such isolated venous emboli \&thrombosis; however CT did not reveal any such occult cause either. So we kept the diagnosis of idiopathic isolated External Jugular Vein Thrombosis.

Now the dilemma was - What to do? Physician was consulted regarding the usefulness of anti-coagulant therapy; however they were not in favor due to long standing history and possibility of well-organized thrombus which to do respond to such oral therapies. At the same time it can be dangerous at that age of the patient, it acts as a double edged sword, and can cause intracranial bleeds. The lesion was also increasing in size and patient was having severe pain. In view of possibility of any thromboembolic event because of this pathology, decision to operate on the patient and excise the lesion was taken.

Patient was operated under general anesthesia. Intra-operatively we could find the thrombosed vein and some chronic inflammation, in addition to this, there was a thickened, inflamed cord-like structure which was going posteriorly towards the vertebral column. It could be traced upto the cervical vertebra. The site was corresponding to the route of Greater Auricular Nerve in the neck. The lesion along with the cord-like structure was removed as far as possible \& sent for histopathological examination. Post-operative period was uneventful except for altered sensation and pain in the distribution of Greater Auricular Nerve further strengthening our belief that the structure was Greater Auricular Nerve.

Histo-pathology report, to our surprise was suggestive of multiple tubercular granulomas involving the neural tissue, surrounding muscles and vessels (Fig. II). Leprosy was ruled out by special stains (Modified Fite method), which is more common in peripheral nerves. The final report given was Tubercular Neuritis involving peripheral Nerve. The entity as such is very rare. The patient was given antitubercular treatment for 6 months (category I) and has responded very well to it. She presently has no symptoms, except for slight hypoesthesia in the distribution of greater auricular nerve and is under regular follow-up (Fig. III).

DISCUSSION: Lymphadenitis is the most frequent presentation of extra-pulmonary tuberculosis. Cervical lymph nodes are the commonest lymph nodes to get involved and present as a neck mass. ${ }^{1}$ However, cervical nerve involvement associated with cervical lymphadenitis is rarely quoted in literature. True infectious diseases of peripheral nerves are rare. Peripheral polyneuropathy commonly occurs following exanthematous fevers and as a complication of various acute bacterial infections. ${ }^{2}$ Midroni $\mathrm{H}$ and Bilbao JM (1995) ${ }^{3}$ have stated that one of the commonest causes of neuropathy is leprosy. 
Neuropathy in patients with tuberculosis was, in the past, mostly attributed to alcohol and malnutrition, and more recently has been attributed to anti-tuberculosis medication, ${ }^{3}$ and a radiculopathy as a result of tuberculous meningitis.

In tuberculosis, cellular response comprises of macrophages and lymphocytes (TH1). The accumulated macrophages transform to epitheloid histiocytes by Interferon-gamma, secreted by TH1 cells and characterized by granulomatous response of tuberculosis. ${ }^{4}$ In the patient we describe, it is not clear, how the granulomata relate to the neuropathic symptoms and signs. Possibilities include a compressive or vascular effect, and also cytokine mediated damage. Mebrotra MP et al (1982) concluded that peripheral nervous system can be directly affected by tuberculosis and neuropathy is attributable to peripheral nerve pressure and direct effects of the tuberculous exudates on the nerve. ${ }^{5}$

Tuberculous neuritis occurring after starting anti-tubercular medication has been studied, especially by Isoniazid and Ethambutol drugs.6,7 Isoniazid combines with pyridoxine, causing a pyridoxine (vitaminB6) deficiency neuropathy that is prevented by co-administration of pyridoxine. Neuropathies are known to occur with Ethambutol and streptomycin. Ethambutol more commonly produces a retrobulbar toxic neuropathy, but may also cause a reversible distal sensory peripheral neuropathy. Streptomycin is vestibulotoxic, but does not cause peripheral neuropathy.7

The association of tuberculosis with Guillain-Barre syndrome is uncertain; although patients have been reported with both conditions coexisting. ${ }^{3}$ Mycobacterium avium-intracellulare has been implicated in neuropathy in patients with HIV. ${ }^{8}$ Lana-Peixoto MA et al (1980) ${ }^{9}$ described isolated tubercular granuloma of the optic nerve in a tuberculous patient. Peripheral neuropathy can also be a rare manifestation of sarcoidosis. Epineural non-caseating granulomas may be found. Sarcoidosis and tuberculosis may occasionally coexist, i.e. tuberculosis may develop after corticosteroid treatment for sarcoidosis, or tuberculosis may masquerade as sarcoidosis. ${ }^{10}$ The temporal relation and response to treatment make additional sarcoidosis unlikely in this patient.

In the present case, the patient had cervical region tuberculosis (?Lymph nodal involvement), which later also involved the adjacentgreat auricular nerve (peripheral nerve)composed of branches of spinal nerves $\mathrm{C} 2$ and C3.This was the cause of her painful neck swelling. There was no evidence of florid tuberculosis elsewhere. Only Greater auricular nerve on left side was found to be involved, associated with peri-neuritis. The possibility is that granulomas disrupted the endoneural blood supply, producing acute Wallerian-type degeneration in the nerve causing pain in the neck.

CONCLUSION: Tuberculosis is a disease with widespread body tissue involvement and show many unusual modes of presentation. High grade of suspicion on the part of specialists and tissue diagnosis becomes imperative in such unusual cases. Good response to anti-tubercular treatment substantiates the diagnosis of tuberculosis in few cases. We have not come across a similar case of cervical nerve involvement in the literature.In our patient; there was definite evidence that the neuropathy preceded the anti-tubercular drug treatment. Neuropathy in patients with tuberculosis is not always iatrogenic, and the possibility of a primary affection of the nerves should be considered.

\section{REFERENCES:}

1. Sharma S. K, Mohan A. Extrapulmonary Tuberculosis. Indian J Med Res 2004; 316-353.

2. Cavanagh JB. The Peripheral Nervous System. In: Symmers W St C, editor. Systemic Pathology, Thirty-eight Authors. $2^{\text {nd }}$ ed. New York: Churchill Livingstone; 1979.p.2296-2348. 


\section{CASE REPORT}

3. Vyravanathan S, Senanayake N. Guillain-Barre syndrome associated with tuberculosis. Postgrad Med J 1983; 59:516-17.

4. McAdam AJ, Sharpe AH. Infectious Diseases. In: Kumar V, Abbas AK, Fausto N, Aster JC, editors. Pathological Basis of Disease. Philadelphia: WB Saunders; 2010.p.331-398.

5. Mebrotra MP, Pursnani ML, Patney NL et al. Tuberculous meningitis: its neurological complications with special reference to their prognostic significance. J Assoc Physicians India 1982; 30:869.

6. Tugwell P, James SL. Peripheral neuropathy with ethambutol. Postgrad Med J 1972; 48(565):667-670.

7. Erdem S, Kissl JT, Mendell JR. Toxic neuropathies: drugs, metals, and alcohol. In: Mendell JR, Kissel JT, Cornblath DR, editors. Diagnosis and Management of peripheral nerve disorders. Oxford: Oxford University Press; 2001.p.297-343.

8. Wrozlek MA, Rao C, Kozlowski PB, et al. Muscle and nerve involvement in AIDS patient with disseminated Mycobacterium intracellulare infection. Muscle Nerve 1989; 12:247-9.

9. Lana-Peixoto MA, Bambirra EA, Pittella JE. Optic nerve tuberculoma. Arch Neurol 1980; 37:1867.

10. Litinsky I, Elkayam O, Flusser G, et al. Sarcoidosis: TB or not TB? Ann Rheum Dis 2002; 61:3856.

\section{AUTHORS:}

1. Vipin R. Ekhar

2. Sachin V. Rane

3. Ritesh N. Shelkar

4. S. K. T. Jain

5. Ashok Garje

\section{PARTICULARS OF CONTRIBUTORS:}

1. Associate Professor, Department of ENT, Indira Gandhi Government Medical College, Nagpur, Maharashtra.

2. Junior Resident, Department of ENT, Indira Gandhi Government Medical College, Nagpur, Maharashtra.

3. Assistant Professor, Department of ENT, Indira Gandhi Government Medical College, Nagpur, Maharashtra.

4. Professor and Head, Department of ENT, Indira Gandhi Government Medical College, Nagpur, Maharashtra.
5. Junior Resident, Department of ENT, Indira Gandhi Government Medical College, Nagpur, Maharashtra.

\section{NAME ADDRESS EMAIL ID OF THE CORRESPONDING AUTHOR:}

Dr. Ritesh Shelkar, \#230, Medical Road, Opposite Ambedkar High School, Untakhana, Nagpur, Maharashtra - 440009.

Email: riteshnshelkar@gmail.com

Date of Submission: 28/04/2014. Date of Peer Review: 29/04/2014. Date of Acceptance: 08/05/2014. Date of Publishing: 13/05/2014. 